\title{
Access to cross-border health care services for patients with rare diseases in the European Union
}

This article was published in the following Dove Press journal:

Orphan Drugs: Research and Reviews

II April 2014

Number of times this article has been viewed

Lise Aagaard'

Kent Kristensen ${ }^{2}$

'Institute of Public Health, Clinical Pharmacology, Faculty of Health

Sciences, ${ }^{2}$ Department of Law, Faculty

of Business and Social Sciences,

University of Southern Denmark,

Odense, Denmark
Correspondence: Lise Aagaard Institute of Public Health, Clinical Pharmacology, Faculty of Health Sciences, University of Southern Denmark, JB Winsløws Vej, 19, 5000 Odense $C$ Denmark Tel +45 65503740

Email laagaard@health.sdu.dk
Abstract: Directive 2011/24/EU may give patients in European Union (EU) member states the right to receive cross-border health care services in other member states reimbursed by their member state of affiliation. For patients with rare diseases, these patient rights could be of relevance, since diagnosis and treatment of rare diseases often requires specialized medical expertise that may not be available to patients in their member state of affiliation. Interpretations of directive 2011/24/ EU, and European case law showed that patients with rare diseases traveling to another member state with the sole purpose of requesting health care services are entitled to have their medical expenses reimbursed by their member state of affiliation if the national health care system cannot provide the required and necessary treatment on its territory within a time limit that is medically justifiable. The decision will be based on an objective medical assessment of the patient's medical condition, the patient's illness, and degree of the patient's pain or the nature of the patient's disability. For inpatients, prior approval from the patients' health insurance system is required. For outpatients, presumably no prior approval is required. However, if outpatient treatment involves the use of expensive equipment and medicines, such as orphan drugs or special training of the medical staff, the member state of affiliation can probably require prior authorization, but this issue remains unanswered. Member states are free to operate with national medication lists with different degrees of reimbursement. For orphan drugs not being reimbursed nationally, member states of affiliation are not obliged to pay for the treatment in another member state. Since directive 2011/24/EU was to be fully implemented in national law by October 2013, experience with this legislation is limited, and therefore future studies of the impact of the legislation on patients' rights in cross-border health care must be conducted.

Keywords: orphan drugs, rare diseases, European Union, cross-border health care

\section{Introduction}

In the European Union (EU), rare diseases are categorized as being rare if they do not affect more than five out of 10,000 patients in the whole EU. The implications of this definition is that between 5,000 and 8,000 different rare diseases affect or will affect around a total of 29 million patients in the whole EU. ${ }^{1}$ Traditionally, patients suffering from rare diseases have been a marginalized patient group because of limited scientific knowledge about the respective diseases, the low number of patients, lack of medical expertise among health care professionals, and restricted awareness about rare diseases in the public, and thus only a few medicines have been marketed for the treatment of rare diseases. ${ }^{1}$ In order to promote and enhance the development of medicines for treatment of rare diseases, a central European licensing system for the approval of orphan drugs was established in 2000 in the EU. ${ }^{2,3}$ 
Orphan drugs are generally higher priced than traditional drugs, due to extra costs in connection with the recruitment of patients for clinical development trials. The high prices have resulted in health authorities in several countries being restrictive in terms of providing public payment for orphan drugs. An example of this is the orphan drug busulfan (Busilvex ${ }^{\circledR}$; Pierre Fabre Médicament, Castres, France), which was approved as conditioning treatment prior to conventional hematopoietic progenitor cell transplantation, but due to the price of treatment of one patient $(>€ 4,400)$, the drug was not reimbursed in Belgium and several Eastern European countries. ${ }^{4,5}$

The Treaty on the Functioning of the European Union (TFEU), Articles 56 and 57 ensures the free movement of goods and health care services between member states. ${ }^{5}$ However, TFEU Articles 114 and 168 also allow member states the right to organize their own health care system in the light of the available national infrastructure and economic resources. ${ }^{5}$ EU directive 2011/24/EU offers patients under specific conditions the right to receive cross-border health care services reimbursed by their member state of affiliation. ${ }^{6}$ For patients with rare diseases, these patient rights may be relevant, since diagnosis and treatment of rare diseases often requires specific medical expertise that may not be available in the patient's member state, but the legal position in this area is not clear. Therefore, we aimed to analyze whether directive 2011/24/ EU gives patients with rare diseases the right to receive health care services in another member state, reimbursed by the member state of affiliation. The study focused on patients who cannot receive the relevant treatment in their member state of affiliation in due time, and then travel to another member state with the sole purpose of receiving reimbursed health care services.

\section{Materials and methods EU legislation on cross-border health care}

Directive 2011/24/EU and regulation (EC) 883/2004 cover issues about patients' rights in cross-border health care. ${ }^{6,7}$ Regulation (EC) 883/2004, which came into force in 2010, has replaced regulation 1408/71 in nearly all aspects. Directive 2011/24/EU and regulation 1408/71 differ in specific areas, ie, the persons covered and reimbursement of costs. Regulation 1408/71 only covers workers, students, and tourists, whereas directive 2011/24/EU covers all patients, hence the objective of this study. In directive 2011/24/EU, the degree of reimbursement of costs is settled according to current rules in patients' member state of affiliation, and in regulation 883/2004 according to the regulation present in the member state, in which the patient receives the health care services. Directive 2011/24/ EU was issued on March 9, 2011, and was to be implemented in national law by October 25, 2013. ${ }^{6,8}$ However, before the implementation deadline, member states could not compromise the directive's objective in cases of grave danger. ${ }^{9}$ The treatment of rare diseases is only mentioned in Article 13 of the directive. This article states that the EU Commission shall support member states in cooperating in the development of, diagnosis, and treatment capacity of rare diseases. In order to achieve this goal, member states shall make health care professionals aware of available tools in order to assist them in the correct diagnosis of rare diseases. The second part of Article 13 states that member states shall make national health bodies responsible for funding of national health care services aware of the possibilities offered by regulation (EC) $883 / 2004$ for referral of patients to other member states for diagnosis and treatment that are not available in the member state of affiliation. ${ }^{10}$

\section{European case law}

Judgments made by the Court of Justice of the European Union (CJEU) are an important source of information in EU case law, which can release legal effects that cannot be read directly from the paragraphs in the various EU regulations and directives. ${ }^{5}$ The CJEU has in a number of cases interpreted regulation (EC) 1408/71, now regulation 883/2004, and defined a number of criteria that will allow patients' crossborder health care services reimbursed by their member state of affiliation. Since no cases concerning patients' access to treatment with orphan drugs have yet been settled at the CJEU, we included all available cases given by the CJEU in cases where member states of affiliation have rejected cover of their citizens' expenses for health care services received in other member states, in the interpretation of directive 2011/24/EU. We also included judgments from the European Free Trade Association (EFTA) Court, even though EU member states are not bound by this court's decisions. ${ }^{5}$ The EFTA judgments are, however, of fundamental character, and therefore these cases were included. The included EFTA cases were the joint cases E-11/07 and E-1/08. ${ }^{11}$ In total, seven CJEU cases were included. In three of the cases, the national health insurance system had refused to grant the patient prior approval to receive reimbursed hospital treatment in another member state: case C-157/99, ${ }^{12}$ case C-368/98, ${ }^{13}$ and case C-56/01. ${ }^{14}$ In the other four cases, the patients' member state of affiliation had refused to cover patients' expenses to hospital services received in another member state without prior approval from the national health care system: case C-385/99, ${ }^{15}$ case 
C-372/04, ${ }^{16}$ case $\mathrm{C}-444 / 05,{ }^{17}$ and case $\mathrm{C}-173 / 09 .{ }^{18}$ In this study, we defined health care services as hospital treatment, since treatment of rare diseases is usually conducted in specialized hospital departments. The CJEU defines a hospital treatment as a health care service, which is performed within a hospital setting. ${ }^{15}$ Additionally, hospital treatment is defined as hospitalization of the patient in question of at least one night of duration. ${ }^{6,14}$

\section{Results}

\section{General principles of directive 20I I/24/EU}

The objective and scope of directive 2011/24/EU is to provide rules for securing access to safe and high-quality crossborder health care services, and to promote cooperation on the exchange of health care services between member states (Article 1). The general principles of reimbursement of costs of cross-border health care services are listed in Article 7(1). If the patient is entitled to the requested health care service(s) on his/her own territory, the member state of affiliation shall ensure that the costs incurred by an insured person who receives cross-border health care are being reimbursed. However, several derogations from Article 7(1) are listed in paragraphs $2-11$. It is for the member state of affiliation to determine the level of health care services for which an insured person is entitled to based on the assumption of costs, and the level of assumption of these costs, regardless of in which member state the health care services were provided (see Article 7[3]).

\section{Prior authorization rules}

The basic premise of directive $2011 / 24 / \mathrm{EU}$ is that member states shall not make reimbursement of costs of cross-border health care services subject to prior authorization; however, this principle is not absolute (Article 7). Article 8 allows for member states to establish national prior authorization systems with the purpose of protecting their national health care systems with respect to planning and securing citizens' permanent access to a number of high-quality treatments. Neither the directive nor the EU case law answers the question of whether patients must pay for the received crossborder health care services by themselves and get reimbursed later, or whether payments must be made beforehand by the national authority. However, it is for the member states to decide whether there is a need to introduce a national system of prior authorization. In Article 44, the directive even mentions the possibility of setting up different criteria for different regions or other relevant administrative levels for the organization of national health care, or indeed for different treatments, as long as the prior authorization system is transparent and easily accessible, and the criteria are made public. Member states may define requirements for prior authorization requirements in the following situations: 1) medical treatments that involve overnight hospital accommodation and/or use of highly specialized and cost-intensive medical infrastructure or medical equipment, 2) medical treatments that involve a particular risk for the patient or population, and 3 ) if the requested health care service is provided by a health care provider that could give rise to serious and specific concerns relating to the quality or safety of the service (see Article 8[2]). According to Article 8(5), member states of affiliation may refuse to grant citizens prior authorization to receive health care services in another member state in the following situations: 1) the requested treatment will expose the patient to an unacceptable patient-safety risk, 2) the general public will be exposed, with reasonable certainty, to a substantial safety hazard as a result of cross-border health care, and 3) the requested health care service can be provided on its own territory within a time limit that is medically acceptable. Directive 2011/24/EU has adopted the CJEU practice in the distinction between hospital and nonhospital health care services for which a system of prior authorization can be established. ${ }^{19}$ Hospitalization of a patient, which involves overnight accommodation, will, according to the CJEU, meet the planning requirements, and therefore be covered by the request of setting of a prior authorization system. Emphasizing the distinctive character of health care services provided in hospitals, the CJEU recognized in case $\mathrm{C}-157 / 99^{12}$ the need for a national prior authorization system in order to ensure a reasonable number of national hospitals distributed geographically in a balanced manner. The use of highly specialized and cost-intensive medical infrastructure or medical equipment refers to the solution derived from C-157/9912 to health care services provided outside the hospital. In judgments C-385/9915 and C-512/08, ${ }^{20}$ the CJEU stated that if an outpatient treatment is performed in a physician's office, but involves the use of specialized medical equipment that is expensive to use and requires special skills of the operating staff, the patient's member state of affiliation may require the setup of an application process involving prior authorization procedures as a part of national planning policy. Among others, the CJEU gave the example of equipment necessary for detecting and treating cancer. ${ }^{20}$ For health care services provided outside hospitals, procedures of prior authorization are according to Article 8(2), limited to a highly 
specialized and cost-intensive medical infrastructure or medical equipment. Therefore, the character of the disease, the necessary equipment, and the required medications determine whether the requirement of a prior authorization can be justified. The derogations in this provision are broad, and indeed many medical and hospital treatments can be seen to fall under this qualification. However, this does not mean that member states are given unfettered discretion, since the CJEU has been prepared to scrutinize the basis on which access to medical treatment is denied by member states. According to directive 2011/24/EU, member states shall notify the European Commission of the setup and design of national prior authorization systems. Additionally, member states are also obliged to make publicly available which type of health care services are subject to such a system. In justifying the requirement for prior authorization, member states must distinguish between the medical infrastructure and equipment, and the medical skills required for the treatment of any ordinary patient treated at a specialized hospital facility. Therefore, if an outpatient is receiving medical treatment at a hospital, the involved medical infrastructure and equipment must also be separated from the facilities used in the treatment of inpatients. Therefore, outpatient health care services involving expensive equipment and medications, and maintained by trained health care professionals at a hospital, will meet the criteria of prior authorization. Hence, patients seeking nonhospital treatment for rare diseases will not need any requirements of prior authorization in cases when the treatment can be easily performed with low complexity involving no expensive equipment and no medical specialists, even though highly qualified medical specialists perform the treatments. For patients with rare diseases, this option could be attractive, particularly for diseases, eg, cancer diagnosis, where the necessary treatment must be delivered within a time limit medically justifiable in order to increase the patients' prognosis of survival. In order to qualify as highly specialized, the treatment has to have a sufficiently high complexity, requiring the involvement of various medical specialists. In the case of outpatients with rare diseases seeking hospital treatment with treatment methods different from the ones used in the member state of affiliation, easy to learn and with a low complexity involving no other medical specialists, the treatment does not fulfill the criteria of being highly specialized, even though it is being performed by a medical specialist. Patients seeking non-hospital medical health care services as part of a treatment they are already being treated for in their member state of affiliation, involving use of medical equipment, several medical specialist and continuous monitoring of the patients, will thus require prior authorization, in order to meet the criteria of necessity, proportionality and the need for national planning.

\section{Recommendation by national physician}

Directive 2011/24/EU does not regulate how the member states shall organize and adapt their supply of hospital services to their citizens. According to directive 2011/24/ EU, recital 37, member states are not excluded from maintaining general conditions and administrative formalities, such as the requirement to consult a general practitioner before consulting a specialist physician. The CJEU has not previously accepted the premise that the patient's health insurance system had set up specific requirements for the prior approval application, eg, that the application should be accompanied by a recommendation made by a national physician. ${ }^{21}$ In case C-368/98, ${ }^{13}$ the CJEU ruled on national law requiring an opinion of a physician practicing in a national university institution, and according to national law, the request for prior authorization was refused on the grounds that the required opinion of a physician practicing in a national university institution had not been submitted. The CJEU did not expressly rule on the legality of the requirement for an opinion from a national established physician or specialist. In general, it is not considered contrary to directive $2011 / 24$ /EU for countries to impose stricter conditions for their own citizens than citizens from other member states. However, the requirement to obtain an opinion from a national physician has a cross-border element excluding physicians' opinions from other member states. In particular, for patients with rare diseases applying for prior authorization, it is stated in Article 8(4) of directive 2011/24/EU that member states can require a clinical evaluation to be carried out by medical experts. The request for prior authorization can only be refused if the derogations in directive 2011/24/EU are met, eg, according to Article 8(6), patient-safety risk to either the patient or the general public. Regarding the freedom to provide services, the CJEU has previously stated that physicians established in other member states must be regarded as providing the same guarantees of professional competence as physicians established in the member state of affiliation. ${ }^{22}$ In case C-145/03, ${ }^{23}$ the CJEU stated that it would be contrary to the principle of mutual recognition of physicians' professional skills not to have the medical recommendation made by a physician authorized in one member state, other than the member state of affiliation, subject for approval of the competent medical institution and the suggested treatment. 
However, the medical evaluations conducted by the specialist physicians must be considered scientifically valid, and internationally recognized.

\section{Discussion}

Patients with rare diseases traveling to another member state with the sole purpose of requesting health care services are entitled to have their medical expenses reimbursed by the member state of affiliation if the national health care system cannot provide the required and necessary treatment on its own territory within a time limit, which is medically justifiable. The decision will be based on an objective medical assessment of the patient's medical condition, the patient's illness, and degree of the patient's pain or the nature of the patient's disability. For patients requiring hospitalization of more than one overnight, prior approval from the patients' health insurance system is required. For outpatients, no acceptance of approval is presumably required; however, if the treatment involves expensive equipment or special medical training, member states can probably set up national systems for prior authorization, though the legal position in this area is not clear.

\section{Reimbursement for orphan drugs}

Despite important efforts to encourage and reward the development of new orphan drugs in the EU and globally, many patients are still waiting for access to relevant treatment, because of a lack of relevant marketed orphan drugs and/or restricted/limited access to marketed orphan drugs due to national reimbursement policies. ${ }^{24,25}$ The high costs and limited available evidence of the efficacy and safety profiles of orphan drugs has led to health authorities in several EU countries being restrictive in their terms of providing public payment. ${ }^{24,25}$ Orphan drugs are often fully reimbursed by the national health care system as a part of the patients' hospital treatment. ${ }^{24,25}$ In some countries, eg, France and the Netherlands, specific recommendation lists issued by the health care authorities exist, and the level of reimbursement of the medications is decided on the basis of these lists. ${ }^{25,26}$ In other countries, eg, Denmark, no specific recommendation list exists for orphan drugs, and public payments of these treatments are decided from case to case. ${ }^{26}$ In some member states, eg, the Eastern European/Baltic countries, only a few of the approved orphan drugs are marketed, and the drugs are only partly reimbursed by the government.

Article 11 of directive 2011/24/EU states that medical prescriptions issued by a licensed physician in one member state should be accepted in other member states on a basis equivalent to prescriptions issued by a nationally located physician. In countries where orphan drugs are not available on the market, it could then be attractive for the patients to receive a prescription from a local physician and travel to another member state in order to buy the requested orphan drug. Since the majority of orphan drugs are marketed with the restriction of only being able to be used in hospitals or by specialist physicians, public access to these medications may therefore be difficult. However, some orphan drugs are available for sale in private pharmacies, ie, Imiglucerase (Cerezyme $^{\circledR}$; Sanofi, Bridgewater, NJ, USA), licensed for the treatment of Gaucher's disease, and colistimethate sodium (Promixin $^{\circledR}$; Swedish Orphan Biovitrum AB, Stockholm, Sweden), used in the treatment of lung infections in patients with cystic fibrosis. ${ }^{3}$ According to Articles 7(3) and 13 of the directive's preamble, obligations of member states to reimburse costs of medicines should be limited to the medicines of which the insured person is entitled to reimbursement, according to national guidelines. Therefore, patients will only be reimbursed for their medical expenses according to principles listed in current national regulations. This principle was also confirmed by case $\mathrm{C}-173 / 09$, in which the CJEU stated that member states of affiliation are free to operate with national reimbursement lists with different degrees of reimbursement for health care services and medicines, meaning that if treatment with orphan drugs is not publicly funded by the member state of affiliation, the patient will not receive reimbursement for the same treatment received in another member state. The only exception is if the requested medical treatment cannot be delivered by the member state of affiliation. In countries where orphan drugs are not publicly funded, patients will not be reimbursed for their medical expenses if they buy the medications in another member state. Reimbursement of patients' treatment with nonlicensed orphan drugs must therefore follow the national rules of each member state, eg, in Denmark, unlicensed use of medications is normally not covered by the national health insurance system, unless the medication is a part of a specialized hospital treatment. In member states like Denmark, where no national reimbursement list for orphan drugs exists, but only internal hospital shopping lists, where orphan drugs traditionally are not listed due to their high price, these internal lists have no legal significance in relation to patients' rights to treatment with orphan drugs. According to directive 2011/24/EU, these medication lists have to be clear with respect to patients' rights to medical treatment. If patients with rare diseases are denied access to treatment with orphan drugs on the basis of internal drug lists, then patients can use the patients' rights 
in directive 2011/24/EU to seek reimbursed treatment in another member state. The argument for this justification is that the requested treatments are not available in the patients' member state of affiliation.

As medication prices in general vary widely between the EU member states, prices of orphan drugs might be higher in economically stronger member states than in economically weaker member states. Therefore, it could be attractive for the national reimbursement systems to encourage patients to have an expensive treatment with orphan drugs in another member state where medication prices are less expensive. As a reaction to this scenario, the marketing authorization holder of the respective orphan drugs may consider increasing prices in the economically weaker member states, or even to withdraw the medicinal product from this market to protect the more profitable sales in economically stronger countries, leaving patients in economically weaker countries without access to life-saving medications. Directive 2011/24/EU does not protect patients with rare diseases against such a scenario, as reimbursement of medications is not a common EU topic, but a national responsibility. Despite important economic efforts to encourage and reward the development of new orphan drugs, many patients are still waiting for access to relevant treatment, because of restricted/limited access to marketed orphan drugs due to national reimbursement policies. ${ }^{27}$

\section{Conclusion}

This is the first study to have interpreted the present EU law on cross-border health care with respect to access to treatment with orphan drugs for patients suffering from rare diseases. The results represent the present legal status, which is characterized by limited legal literature and CJEU practice. Patients' demands for unconditional access to life-saving medications will probably lead to more pressure on the national health care budgets, and therefore more cases at the EU Court, due to difficulties in interpretation of the various paragraphs in directive 2011/24/ EU. Directive 2011/24/EU gives patients with rare diseases, under limited conditions, the right to receive medical treatment in another member state reimbursed by the patients' member state of affiliation. Since directive 2011/24/EU was to be fully implemented in national law by October 2013, experience with this legislation is limited, and therefore future studies of the impact of this legislation on patients' rights in cross-border health care must be conducted.

\section{Author contributions}

LA and KK designed the study, analyzed the data, and wrote the first version of the manuscript. Both authors saw and approved the final version of the manuscript. No sources of funding were used to assist in the preparation of this study.

\section{Disclosure}

The authors have not received reimbursements, fees, funding, or salary from an organization that may in any way gain or lose financially from the publication of this manuscript, either now or in the future. The authors declare no other nonfinancial competing interests.

\section{References}

1. Joppi R, Bertele V, Garattini S. Orphan drugs, orphan diseases. The first decade of orphan drug legislation in the EU. Eur J Clin Pharmacol. 2013;69:1009-1024.

2. Eur-Lex.europa.eu [website on the Internet]. Regulation (EC) no 141/2000 of the European Parliament and of the council of 16 December 1999 on orphan medicinal products. 1999. Available from: http://eur-lex. europa.eu/LexUriServ/LexUriServ.do?uri=celex:32000r0141:en:html. Accessed February 8, 2014.

3. European Commission. Pharmaceuticals - community register. Available from: http://ec.europa.eu/health/documents/communityregister/html. Accessed February 8, 2014.

4. Eur-Lex.europa.eu [website on the Internet]. Richtlinie 2001/38/EG des Europäischen Parlaments und des Rates vom 5. Juni 2001 zur Änderung der Richtlinie 93/7/EWG des Rates über die Rückgabe von unrechtmäßig aus dem Hoheitsgebiet eines Mitgliedstaates verbrachten Kulturgütern (Text von Bedeutung für den EWR) [Directive 2001/83/ EC/EU of the European Parliament and of the Council of 6 November 2001 on the Community code relating to medicinal products for human use]. 2001. Available from: http://eur-lex.europa.eu/LexUriServ/LexUriServ.do?uri=celex:3200110038:de:html. Accessed February 8, 2014. German.

5. European Commission. The Treaty of Lisbon. 2009. Available from: http:// europa.eu/lisbon_treaty/index_en.htm. Accessed February 8, 2014.

6. European Commission. Cross-border healthcare: patients' rights. 2011. Available from: http://europa.eu/legislation_summaries/ employment_and_social_policy/social_protection/sp0002_en.htm. Accessed February 8, 2014.

7. Eur-Lex.europa.eu [website on the Internet]. Regulation (EEC) no 1408/71 of the council of 14 June 1971 on the application of social security schemes to employed persons and their families moving within the community. 1971. Available from: http://eur-lex.europa.eu/LexUriServ/LexUriServ. do?uri=celex:31971r1408:en:html. Accessed February 8, 2014.

8. Court of Justice of the European Union. Judgment of the court of 5 April 1979. Criminal proceedings against Tullio Ratti. Reference for a preliminary ruling: Pretura di Milano - Italy. Dangerous preparations. Case 148/78. 1979. Available from: http://curia.europa.eu/juris/celex. jsf?celex $=61978$ CJ0148\&lang $1=$ da\&type $=$ NOT\&ancre $=$. Accessed February 8, 2014.

9. Court of Justice of the European Union. Judgment of the court of 18 December 1997. Inter-Environnement Wallonie ASBL v Région Wallonne. Reference for a preliminary ruling: Conseil d'Etat - Belgium. Directive 91/156/EEC - period for transposition - effects - definition of waste. Case C-129/96. 1997. Available from: http://curia.europa.eu/ juris/celex.jsf?celex $=61996$ CJ0129 $\&$ lang $1=$ da\&type $=$ NOT $\&$ ancre $=$. Accessed February 8, 2014.

10. European Commission. Regulation (EC) no 883/2004 of the European Parliament and of the council of 29 April 2004 on the coordination of social security systems (text with relevance for the EEA and for Switzerland). 2004. Available from: http://eur-lex.europa.eu/LexUriServ/LexUriServ. do?uri=CELEX:32004R0883:en:NOT. Accessed February 8, 2014. 
11. EFTA Court. E-11/07 and E-1/08 - Olga Rindal and Therese Slinning v Staten v/Dispensasjons - og klagenemnda for bidrag til behandling i utlandet [Olga Rindal (Case E-11/07); Therese Slinning (represented by legal guardian Olav Slinning (Case E-1/08)]. Available from: http://www. eftacourt.int/cases/detail/?tx_nvcases_pi1[case_id] $=178 \& \mathrm{cHash}=\mathrm{f} 623 \mathrm{f}$ d1614040dd1cf10ef298a057e7. Accessed February 8, 2014. Danish.

12. Court of Justice of the European Union. Case C-157/99: Smits and Peerbooms. 2001. Available from: http://curia.europa.eu/juris/liste. jsf?language $=$ en $\&$ jur $=\mathrm{C}, \mathrm{T}, \mathrm{F} \&$ num $=\mathrm{C}-157 / 99 \& \mathrm{td}=\mathrm{ALL}$. Accessed February 8, 2014.

13. Court of Justice of the European Union Case C-368/98: Judgment of the court of 12 July 2001. Abdon Vanbraekel and Others v Alliance Nationale des Mutualités Chrétiennes (ANMC). Reference for a preliminary ruling: cour du travail de mons - Belgium. Social security sickness insurance articles 22 and 36 of regulation (EEC) no 1408/71 - freedom to provide services - article 59 of the EC treaty (now, after amendment, article 49 EC) - hospital treatment costs incurred in another member state-refusal of authorisation subsequently declared unfounded. 2001. Available from: http://curia.europa.eu/juris/celex.jsf?celex=61998CJ0368\&lang1=da\&ty pe $=$ NOT\&ancre $=$. Accessed February 8, 2014.

14. Court of Justice of the European Union. Case 56/01: Patricia Inizan v Caisse Primaire d'Assurance Maladie des Hauts-de-Seine. 2003. Available from: http://curia.europa.eu/juris/celex.jsf?celex=62001CJ0056\& lang1=da\&type=NOT\&ancre $=$. Accessed February 8, 2014.

15. Court of Justice of the European Union. Freedom to provide services articles 59 of the EC treaty (now, after amendment, article 49 EC) and 60 of the EC treaty (now article 50 EC) - sickness insurance - system providing benefits in kind - system of agreements - medical costs incurred in another member state - prior authorisation - criteria - justification. 2003. Available from: http://curia.europa.eu/juris/document/document. jsf?text $=\&$ docid $=48278 \&$ pageIndex $=0 \&$ doclang $=$ EN\&mode $=1$ st $\&$ dir $=$ \&occ=first\&part=1\&cid=168505. Accessed February 8, 2014.

16. Court of Justice of the European Union. Social security - national health system funded by the state - medical expenses incurred in another member state - articles $48 \mathrm{EC}$ to $50 \mathrm{EC}$ and 152(5) EC - article 22 of regulation (EEC) no 1408/71. 2006. Available from: http://curia.europa. eu/juris/document/document.jsf?text $=\&$ docid $=56965 \&$ pageIndex $=0 \& d$ oclang=EN\&mode $=1$ st $\&$ dir $=\&$ occ $=$ first $\&$ part $=1 \&$ cid $=16870$. Accessed February 8, 2014.

17. Court of Justice of the European Union. Restrictions on the freedom to provide services - reimbursement of the cost of treatment in private hospitals - justification for, and proportionality of, the exclusion. 2007. Available from: http://curia.europa.eu/juris/document/document.jsf?te $\mathrm{xt}=\&$ docid $=60930$ \&pageIndex $=0$ \&doclang $=\mathrm{EN} \&$ mode $=1$ st \&dir $=\&$ oc $\mathrm{c}=$ first\&part=1\&cid=168860. Accessed February 8, 2014.

18. Court of Justice of the European Union. Social security - freedom to provide services - sickness insurance - hospital treatment provided in another member state - prior authorisation - conditions of application of the second subparagraph of article 22(2) of regulation (EEC) no $1408 / 71$ - methods of reimbursement to the insured person of hospital expenses incurred in another member state - obligation on a lower court to comply with the directions of a higher court. 2010. Available from: http://curia.europa.eu/juris/document/document.jsf?text=\&docid=813 96\&pageIndex $=0 \&$ doclang $=\mathrm{EN} \&$ mode $=1 \mathrm{st} \&$ dir $=\&$ occ $=$ first $\&$ part $=1 \&$ cid=169175. Accessed February 8, 2014.
19. De La Rosa S. The directive on cross-border health care or the art of codifying complex case law. Common Mark Law Rev. 2012;49:15-46.

20. Court of Justice of the European Union. Failure of a member state to fulfil obligations - article $49 \mathrm{EC}$ - social security - medical treatment proposed in another member state and requiring the use of major medical equipment - requirement of prior authorisation - planned treatment provided in another member state - difference in the levels of cover in force in the member state of affiliation and in the member state of stay, respectively - insured person's right to assistance by the competent institution to supplement that of the institution of the member state of stay: case C-512/08. 2010. Available from: http://curia.europa.eu/juris/ liste.jsf?language $=$ en $\&$ jur $=\mathrm{C}, \mathrm{T}, \mathrm{F} \&$ num $=\mathrm{C}-512 / 08 \& \mathrm{td}=\mathrm{ALL}$. Accessed February 8, 2014.

21. Court of Justice of the European Union. Freedom to provide services reimbursement of medical expenses incurred in another member state - prior authorisation of the competent institution - public health dental treatment. 1998. Available from: http:/curia.europa.eu/juris/ document/document.jsf?text $=\&$ docid $=43793 \&$ pageIndex $=0 \&$ docla ng $=$ EN\&mode $=1$ st \&dir $=\&$ occ $=$ first $\&$ part $=1 \&$ cid $=170853$. Accessed February 8, 2014.

22. European Commission. The EU single market: legislation (free movement of professionals). Available from: http://ec.europa.eu/ internal_market/qualifications/policy_developments/legislation/ index_en.htm. Accessed February 8, 2014.

23. Court of Justice of the European Union. CaseC-145/03: Heirs of Annette Keller v Instituto Nacional de la Seguridad Social (INSS) and Instituto Nacional de Gestión Sanitaria (Ingesa). 2005. Available from: http:// curia.europa.eu/juris/document/document.jsf?text=\&docid=49827\& pageIndex $=0 \&$ doclang $=E N \&$ mode $=1$ st $\&$ dir $=\& o c c=$ first $\&$ part $=1 \& \mathrm{ci}$ d=170951. Accessed February 8, 2014.

24. Hemstra H. Variations in access and use of orphan drugs among EU member states. Eur J Hosp Pharm Sci Pract. 2010;16:25-27.

25. Roll K, Stargardt T, Schreyögg J. [Authorization and reimbursement of orphan drugs in an international comparison]. Gesundheitswesen. 2011;73:504-514. German.

26. Ministry of Health and Prevention. Danish Health Act: consolidated act no 913 of 13 July 2010. 2010. Available from: https://www.retsinformation. dk/Forms/R0710.aspx?id=130455. Accessed February 8, 2014.

27. European Commission. Authorisation and supervision of medicinal products - European Medicines Agency. 2011. Available from: http:// europa.eu/legislation_summaries/internal_market/single_market_ for_goods/pharmaceutical_and_cosmetic_products/122149_en.htm. Accessed February 8, 2014.
Orphan Drugs: Research and Reviews

\section{Publish your work in this journal}

Orphan Drugs: Research and Reviews is an international, peer-reviewed, open access journal publishing original research, reports, reviews and commentaries on all areas of the design and development of orphan drugs for the treatment of rare diseases through to clinical applications. Clinical outcomes, patient safety, and programs for the development and

\section{Dovepress}

effective, safe, and sustained use of medicines will be a feature of the journal. The manuscript management system is completely online and includes a very quick and fair peer-review system, which is all easy to use. Visit http://www.dovepress.com/testimonials.php to read real quotes from published authors. 